\title{
Detection and abundance estimation of euphausiids using an optical plankton counter
}

\author{
Alex W. Herman ${ }^{1}$, N. A. Cochrane ${ }^{1}$, D. D. Sameoto ${ }^{2}$ \\ ${ }^{1}$ Physical and Chemical Sciences Branch, ${ }^{2}$ Biological Sciences Branch, \\ Bedford Institute of Oceanography, Dept of Fisheries and Oceans, PO Box 1006, Dartmouth, Nova Scotia, Canada B2Y 4A2
}

\begin{abstract}
An optical plankton counter (OPC) mounted on a towed Batfish vehicle was used to detect and estimate the abundance of euphausiids in the Emerald and La Have Basins of the Scotian Shelf, northwest Atlantic Ocean. Euphausiids (Meganyctiphanes norvegica and Thysanoessa inermis) were identified from their characteristic diameter distributions measured by the OPC. The diameter distributions containing euphausiid peaks were compared to several depth strata known to contain these animals. The depth strata containing euphausids were established from acoustical tows made on the same cruise and the identification of animals was accomplished by sampling these acoustical layers with the BIONESS net sampler. The diel migration patterns of the euphausids were also identified from these diameter distributions. Euphausiid reaction to artificial lights mounted on Batfish and BIONESS showed increases in abundance estimates by a factor of $2 x$ and $50 x$ respectively. Experiments with artificial lights mounted on a remotely operated vehicle and camera platforms are also described. An artificial light mounted on a towed Batfish resulted in a distinct increase in euphausiid abundance estimates as measured by the OPC. Abundance estimates from the OPC are also compared to results from acoustical tows and showed agreement to within a factor of 2 and better.
\end{abstract}

\section{INTRODUCTION}

The estimation of euphausiid abundance has been made traditionally by plankton net hauls and by acoustic backscattering measurements. Conventional plankton nets such as the ring and bongo nets and the more recent high technology systems such as BIONESS (Sameoto et al. 1980) and MOCNESS (Wiebe et al. 1976) still have problems of net avoidance by larger euphausiids (Everson \& Bone 1986, Sameoto et al. 1990, Cochrane et al. 1991). Acoustical estimates are derived from 2 methods, the multiple-frequency (Greenlaw 1979, Holliday 1980, Holliday \& Pieper 1980, Pieper \& Holliday 1984) and the dual beam technique (Richter 1985, Greene et al. 1989). Multiplefrequency techniques rely on frequency-dependent backscattering models to partition volume backscattering data into size classes. The dual-beam technique is a more direct method which enables the analysis of single echoes from individual animals and therefore the determination of target strength. One of the major problems in accurate acoustical estimates is the unknown parameter of animal orientation (Sameoto et al. 1985) which can result in target strength uncertainties of up to $10 \mathrm{db}$.

We report here on the detection of euphausiids by an optical method. The optical plankton counter (OPC) developed at the Bedford Institute of Oceanography (Herman 1988, 1992) has been used primarily for the detection and abundance estimation of copepods (Herman et al. 1991) ranging from the smallest detectable sizes of $250 \mu \mathrm{m}$ to the largest Calanus spp. of about $4 \mathrm{~mm}$ in length for which the present OPC is tuned. The OPC has never been applied to the problem of euphausiid detection due to (1) the typically low euphausiid concentration (relative to copepods), (2) their avoidance capabilities, and (3) our lack of knowledge of the OPC dynamic response to their shapes. We report on the OPC identification of 2 species, Meganyctiphanes norvegica and Thysanoessa inermis, found in the La Have and Emerald Basins of the Scotian Shelf, northwest Atlantic Ocean, which 
could be identified by their dimensional properties alone. We examine diameter distributions for each species and show how dominant peaks emerge in the distributions within different depth strata and for day/night periods indicating diel migration. By comparing these data to BIONESS net hauls (Sameoto et al. 1993), we were able to identify these peaks as belonging to $M$. norvegica and $T$. inermis.

Our sampling method employed an OPC mounted on a Batfish vehicle towed at high speeds. Abundance estimates made by the OPC were compared to those made from acoustic backscattering measurements using 50 and $200 \mathrm{kHz}$ transducers towed simultaneously with the Batfish. We report on an experiment performed with bright lights (quartz-halogen) mounted on the Batfish and designed to reduce avoidance. Results from all 3 methods, the Batfish/OPC and acoustic measurements are intercompared. Collection statistics and methods for an OPC mounted on the BIONESS sampler are discussed.

\section{SAMPLING AREA AND METHODS}

Sampling occurred between 25 September and 5 October 1990 on the research vessel CSS 'Dawson' in the Emerald and La Have Basins located within the Scotian Shelf between $43^{\circ}$ to $44^{\circ} \mathrm{N}$ and $62^{\circ}$ to $64^{\circ} \mathrm{W}$. These basins harbor large aggregations of euphausiids and copepods below $200 \mathrm{~m}$ depth (Sameoto \& Herman 1990, Herman et al. 1991).

Euphausiids were detected and measured by an optical plankton counter (OPC) employing the new high sensitivity design reported in Herman (1992). The OPC is capable of detecting plankton/particles in a size range from $250 \mu \mathrm{m}$ to 2 $\mathrm{cm}$. The OPC is able to identify the dominant species of a sample population by identification of dominant peaks within its diameter distribution (Herman 1988, 1992, Herman et al. 1991).

The OPC was mounted on a Batfish vehicle while towed at speeds of $4 \mathrm{~m} \mathrm{~s}^{-1}$ behind a ship in a sawtooth undulating pattern cycling between 10 and $250 \mathrm{~m}$ depth. The horizontal cycling distances depended on the diving depth and diving rates where the average cycle distance was about $1.5 \mathrm{~km}$.
The Batfish carried an array of sensors described in Herman \& Dauphinee (1980) consisting of: (1) a Variosens fluorometer measuring chlorophyll a, (2) a digital CTD probe measuring conductivity, temperature and depth and (3) an OPC.

Euphausiid sampling was performed within the La Have Basin. Avoidance experiments and comparison to acoustical tows were accomplished by cycling the Batfish between 180 and $220 \mathrm{~m}$ in the scattering layers containing Meganyctiphanes norvegica. A quartzhalogen light was mounted just above the OPC (Fig. 1) allowing us to assess the effect of bright lights on euphausiid avoidance. These measurements are patterned after similar experiments performed with the BIONESS sampler (Sameoto et al. 1990, 1993). A clear acrylic fairing was placed in front of the quartzhalogen light to reduce drag.

Acoustical data were gathered on 2 frequencies simultaneously with Batfish/OPC tows. Downwarddirected sonar transducers operating at 50 and $200 \mathrm{kHz}$ were towed at 6 to $7 \mathrm{~m}$ depth below the surface bubble layer. Assuming a population of identical scatterers, volume backscattering strengths calculated with Francois \& Garrison (1983a, b) were related to organism number and organism target strength. Acoustical target strengths for volume backscattering

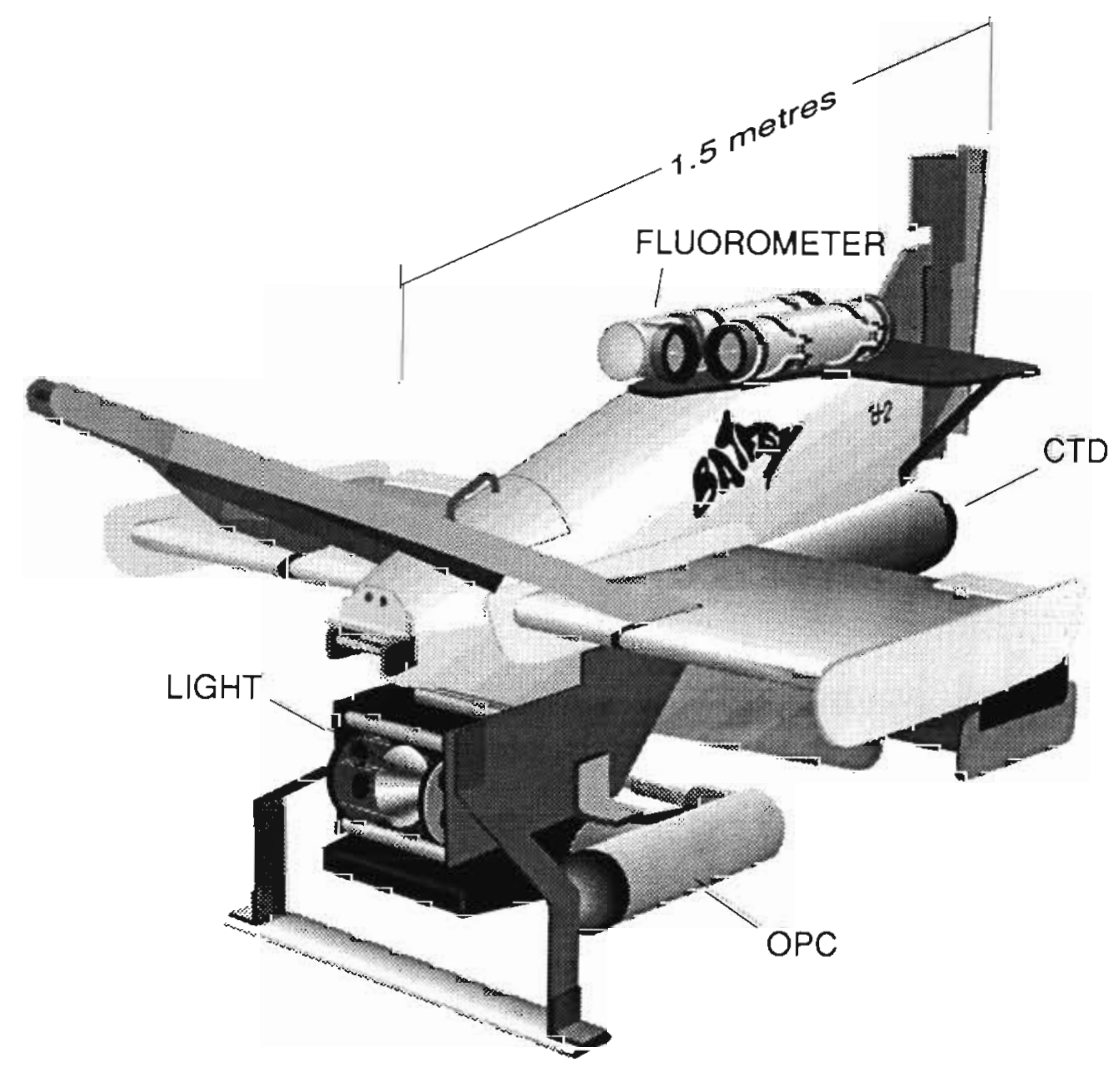

Fig. 1. The Batfish vehicle shawing artificial lights installed above the OPC 
strength inversion were calculated using the statistically oriented high pass fluid cylinder models as described by Cochrane et al. (1991). In this case an orientational standard deviation of $5^{\circ}$ and a mean length of $2.8 \mathrm{~cm}$ for Meganyctiphanes norvegica was used in the acoustical model (Sameoto et al. 1993).

Video observations of euphausiid behaviour near the bottom of La Have Basin were made with a black and white Sony video camera mounted on a $1 \times 1 \mathrm{~m}$ open-box frame. The light source used on Batfish was also mounted on the video frame normal to the camera axis in the horizontal plane. The frame was lowered to rest on the bottom of both La Have or Emerald Basins at a depth of $270 \mathrm{~m}$ and used to observe the reaction of euphausiids to the lights. The video camera was also mounted on the HYSUB 5000 ROV (a remote-controlled submersible) to observe euphausiid reaction within the basins.

\section{EUPHAUSIID IDENTIFICATION AND DIAMETER CALIBRATIONS}

\section{Mapping of euphausiid layers}

The first step in assessing the potential of the OPC for identifying euphausiids was to obtain data from specific regions and depth strata that were known to contain structured layers. This information was obtained from acoustic tows and BIONESS net hauls performed during the cruise (Cochrane et al. 1991, Sameoto et al. 1993). The La Have Basin contained Meganyctiphanes norvegica adults with concentrations of ca $5 \mathrm{~m}^{-3}$. $M$. norvegica were located below $160 \mathrm{~m}$ depth during daytime and migrated to the upper layers from 0 to $50 \mathrm{~m}$ at night. Thysanoessa inermis adults were found within the depth range of 70 to $100 \mathrm{~m}$ during daytime and were aggregated in narrow layers of 10 to $20 \mathrm{~m}$ thickness. At night $T$. inermis migrated to the upper $50 \mathrm{~m}$ while approximately two-thirds of the population were concentrated between 40 and $50 \mathrm{~m}$ depth.

These were the general features observed in the populations of Meganyctiphanes norvegica and Thysanoessa inermis, however there were some deviations from these patterns. Approximately $20 \%$ of the water column population of Thysanoessa spp. were found to co-habit the same depth region as $M$. norvegica, i.e. below $160 \mathrm{~m}$. Approximately $25 \%$ of Thysanoessa spp. were $T$. longicaudata, a species approximately $20 \%$ smaller in mean diameter than $T$. inermis.

\section{OPC measurement response to euphausiids}

Identifying both Meganyctiphanes norvegica and Thysanoessa inermis with the OPC was accomplished by first estimating their 'mean' diameters from microscopic measurements and then comparing these measurements to the OPC-measured diameter distributions. The OPC calibration is based on response to spherical beads (Herman 1992) and the resultant calibration equation predicts the equivalent spherical diameter of the zooplankter detected. These calibrations apply to the new design of OPC (Herman 1992) which employs a narrow light beam of $4 \mathrm{~mm}$ width and $20 \mathrm{~mm}$ height. Most copepods, including the largest Calanus spp., would be enveloped by the width of the beam during passage while the OPC measures the maximum cross-sectional area of a copepod present in the beam. We can equate this cross-sectional area of the animal in the beam, $A_{x}$, to the cross-sectional area of a sphere (Herman 1992) and we can obtain the equivalent spherical diameter, ESD, from

$$
\mathrm{ESD}=\sqrt{A_{\times} 4 / \pi}
$$

Euphausiids however, with typical body lengths of ca $2 \mathrm{~cm}$, would overlap the beam width during passage. It was necessary, therefore, to estimate geometrically the area, $A_{X}$, and finally the ESD of a euphausiid that would be measured by the OPC beam in order to compare it to the ESD actually measured by the OPC. Since the OPC beam would measure the maximum cross-sectional area of the euphausiid during passage through the beam, that area would be represented by the beam width (i.e. $4 \mathrm{~mm}$ ) multiplied by the maximum thoracic width of the animal. In the case of Meganyctiphanes norvegica, there were 3 distinct size groups of adults with thoracic widths of $1.2,2.2$ and $3.5 \mathrm{~mm}$ (corresponding lengths of 10,16 and $26 \mathrm{~mm}$ respectively). By multiplying their thoracic widths by the beam width of $4 \mathrm{~mm}$, we obtained the maximum area, $A_{x}$, measured by the beam. By substituting $A_{\mathrm{x}}$ into Eq. 1, we obtained their corresponding ESD values of $2.5,3.4$ and $4.3 \mathrm{~mm}$. The 2 largest size groups with $\mathrm{ESD}=3.4$ and $4.3 \mathrm{~mm}$ comprised ca two-thirds of the total. When examining the OPCmeasured diameter distributions therefore, we would expect to find $M$. norvegica between ca 3 and $6 \mathrm{~mm}$ ESD.

In the case of Thysanoessa inermis, there was 1 dominant size of adults with a thoracic width of ca $1.2 \mathrm{~mm}$ and a resultant ESD of $2.5 \mathrm{~mm}$. Therefore we would expect to find $T$. inermis between ca 2 and $3 \mathrm{~mm}$ when examining the OPC-measured diameter distributions.

\section{OPC field measurements of diameter distributions}

To locate euphausiid peaks within diameter distributions measured by the OPC, we can now use the 
following information, i.e. (1) the depth regions containing the euphausiid layer known from acoustic and BIONESS tows and (2) the expected diameter ranges in which the euphausiid peaks will occur. Batfish Tows 8 and 9 represent a total of 36 and 18 profiles respectively sampled by the OPC in the La Have Basin during day and night respectively. Fig. 2 shows the diameter distributions (ESD) for a depth range of 70 to $100 \mathrm{~m}$ where we expected to find Thysanoessa inermis during daytime. The 'counts' scale is expanded to enhance the regions of low count rates. The diameter region of 0 to $1.5 \mathrm{~mm}$ shows a single peak which is offscale and therefore does not illustrate any structure. When properly scaled, however, this peak will exhibit several defined peaks belonging to the various stages of Calanus finmarchicus and other smaller copepods as shown in Herman (1992). The daytime distribution in Fig. 2 shows defined peak structure(s) between ca 1.8 and $3 \mathrm{~mm}$, i.e. in a diameter and depth region where we would expect to find $T$. inermis. The peak area corresponds to a total of ca 350 animals. The nighttime diameter distributions show a significant reduction in the peak corresponding to the known migration of $T$. inermis into the upper layers. Note also the increase in counts in the region above $3 \mathrm{~mm}$ (nighttime) which we later identify as belonging to $M$. norvegica. Fig. 3 represents

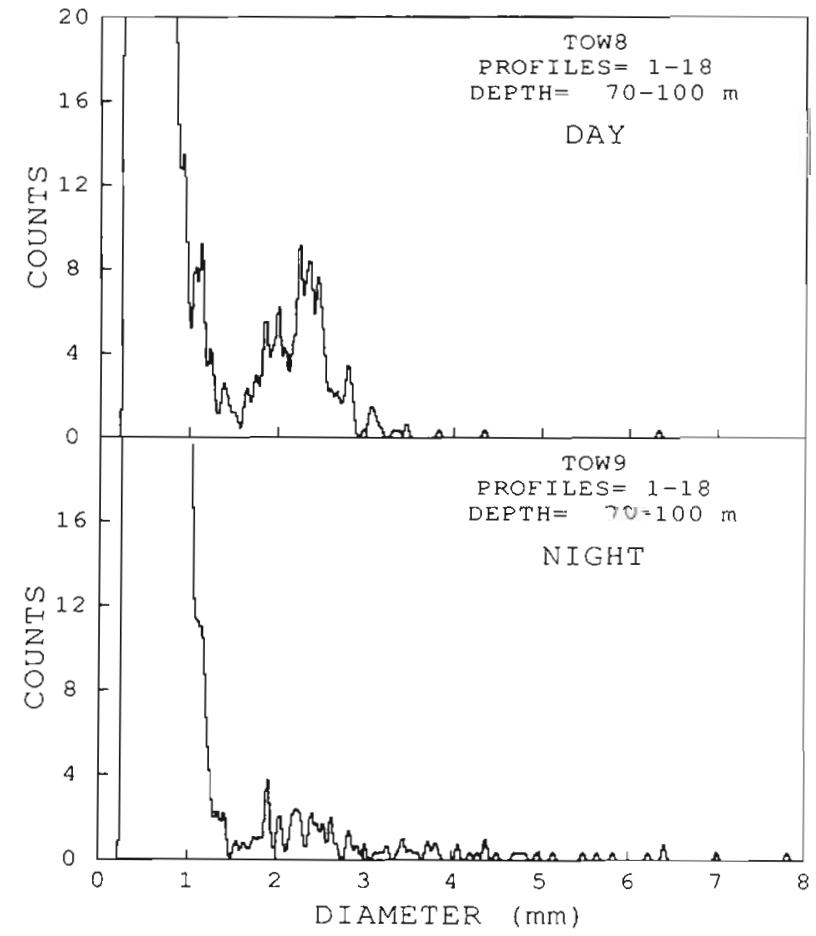

Fig. 2. Day and night diameter distributions sampled with the Batfish/OPC and plotted only for the depth region between 70 and $100 \mathrm{~m}$. The peak between 1.8 and $3.0 \mathrm{~mm}$ ESD in the day sample corresponds to Thysanoessa inermis

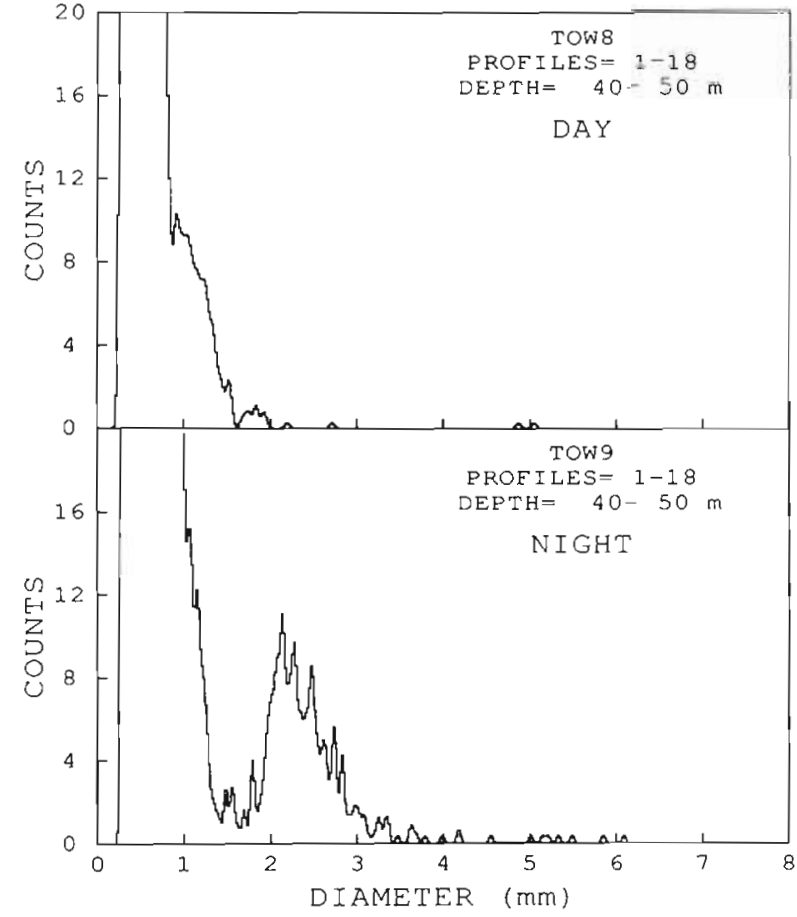

Fig. 3. Day and night diameter distributions sampled with the Batfish/OPC and plotted only for the depth region between 40 and $50 \mathrm{~m}$. The peak between 1.8 and $3.0 \mathrm{~mm}$ in the night sample indicates the migration of Thysanoessa inermis

the diameter distribution from the same tows for the depth region 40 to $50 \mathrm{~m}$ where we expected to observe nighttime migration. The nighttime distribution shows a well-defined peak between 1.8 and $3 \mathrm{~mm}$ corresponding to $T$. inermis which have undergone migration mostly from the 70 to $100 \mathrm{~m}$ depth region. The daytime distribution of Fig. 3 shows an absence of the same peak.

Fig. 4 shows the diameter distributions from the depth region 170 to $200 \mathrm{~m}$ where we expected to find Meganyctiphanes norvegica. Here we see a diffuse peak distributed between ca 3 and $6 \mathrm{~mm}$ which corresponds to the 3 size groups belonging to $M$. norvegica adults. This peak area corresponds to a total of ca 250 animals. The region between ca 2 and $3 \mathrm{~mm}$ contains some counts which we ascertain to belong to Thysanoessa inermis or the smallest size group of $M$. norvegica. The nighttime distribution above $2 \mathrm{~mm}$ clearly shows an absence of any counts. Fig. 5 shows the diameter distribution for the depth region 0 to $40 \mathrm{~m}$ where we expected to find nighttime migration of $M$. norvegica. The nighttime distribution shows a broad diffuse peak above $2 \mathrm{~mm}$. Here we can only assume that the region between 1.8 and $3 \mathrm{~mm}$ was dominated by $T$. inermis while the region between 3 and $6 \mathrm{~mm}$ was dominated by M. norvegica. 


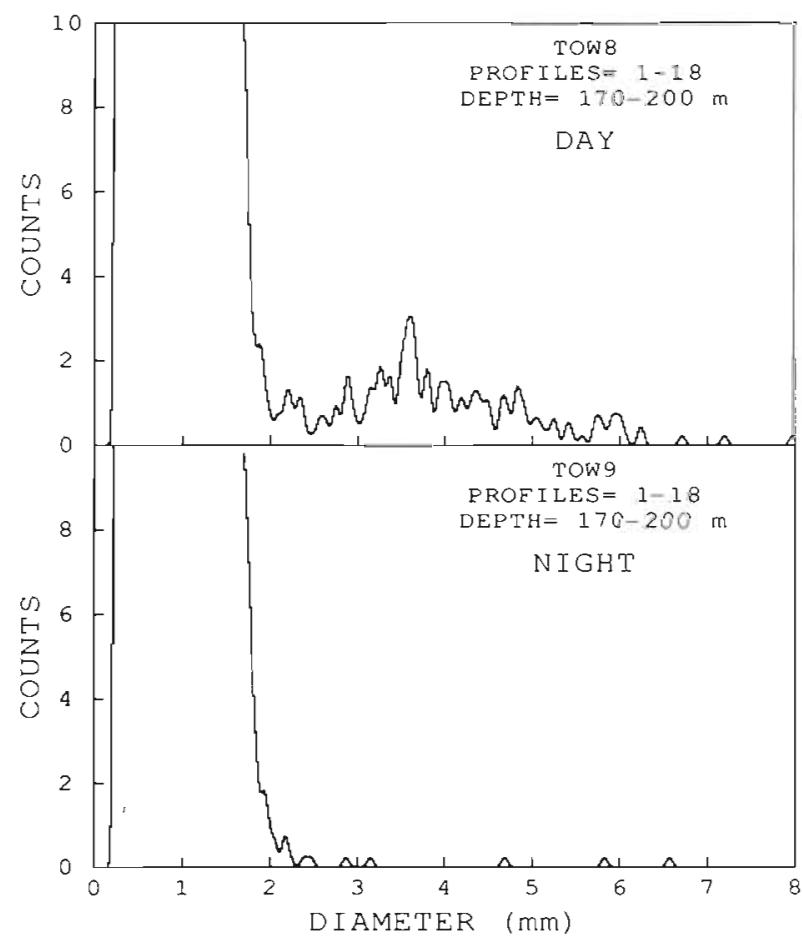

Fig. 4. Day and night diameter distributions sampled with the Batfish/OPC and plotted for the depth region between 170 and $200 \mathrm{~m}$. The diffuse peak between 3.0 and $6.0 \mathrm{~mm}$ corresponds to Meganyctiphanes norvegica

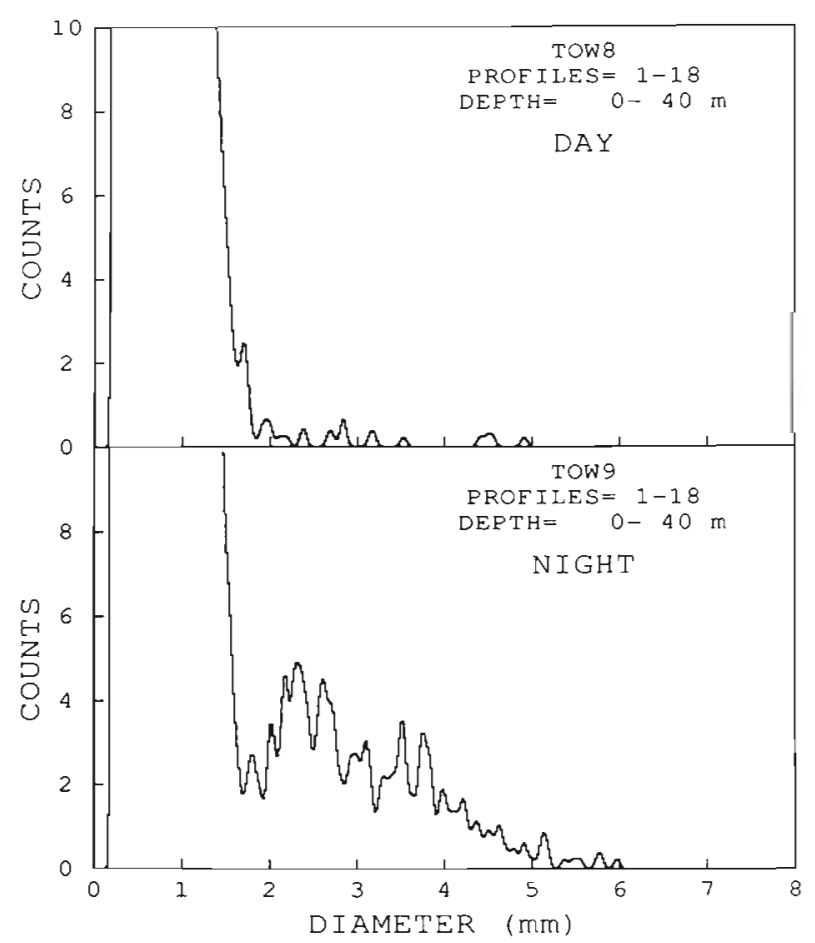

Fig. 5. Day and night diameter distributions sampled with the Batfish/OPC and plotted for the depth region between 0 and $40 \mathrm{~m}$. The peak between 2.0 and $6.0 \mathrm{~mm}$ corresponds to both Thysanoessa inermis and Meganyctiphanes norvegica

\section{PROFILES OF MEGANYCTIPHANES NORVEGICA IN LA HAVE BASIN}

The entire transect sampled by Batfish (Tow 8) consisted of 36 profiles encompassing a distance of ca $55 \mathrm{~km}$ (Fig. 6). Only those OPC counts within the diameter window of 3 to $6 \mathrm{~mm}$ corresponding to Meganyctiphanes norvegica were processed and contoured on depth using a 3-dimensional perspective plot. Most of the $M$. norvegica layer was not clearly defined or uniform but rather consisted of a series of euphausiid groups or 'clusters' of ca 1 to $3 \mathrm{~m}$ in the vertical scale. Peak concentrations in such groups ranged from 50 to $600 \mathrm{~m}^{-3}$, however, mean concentrations averaged over the layer depth from ca 170 to $210 \mathrm{~m}$ were ca $5 \mathrm{~m}^{-3}$. Some scattered groups of $M$. norvegica were measured also at midwater depths (Fig. 6).

\section{EUPHAUSIID RESPONSE TO ARTIFICIAL LIGHTS}

Video observations using a HYSUB 5000 ROV were made in Emerald Basin during June 1989. The response of Meganyctiphanes norvegica to bright lights mounted on the ROV yielded several observations. In the first case while the ROV was moving at any speed, that is, from drifting slowly to full speed (ca 3 knots), euphausiids were not attracted to nor avoided the ROV but simply moved about in a 'business as usual' manner. However once the ROV was motionless, euphausiids aggregated around the light after a 'stabilization' period of $1 \mathrm{~min}$. These observations were confirmed by experiments with a black and white video camera mounted on a platform and lowered to the bottom of Emerald Basin.

To observe the effect of bright lights on sampling euphausiids, Sameoto et al. (1990) attached a $150 \mathrm{~W}$ tungsten-halogen lamp to the BIONESS multiple-net sampler system. He observed a consistent increase by a factor of 10 to 40 in euphausiid catches during the day. Their estimates of Meganyctiphanes norvegica made with the BIONESS using bright lights were now more consistent with acoustic measurements (Sameoto et al. 1993).

To test the avoidance of Meganyctiphanes norvegica to the Batfish, a $300 \mathrm{~W}$ tungsten-halogen lamp was mounted above the OPC. The Batfish was then deployed and set to cycle between 180 and $220 \mathrm{~m}$ (as shown in Fig. 7) while towed over a distance of ca $25 \mathrm{~km}$. The selected depth range corresponded to scattering layers identified by the 50 and $200 \mathrm{kHz}$ transducers towed simultaneously with Batfish. For each of 3 Batfish cycles, the lights were alternated between 'on' and 'off' positions for a total of 15 times. The euphausiid concentration was calculated for each 


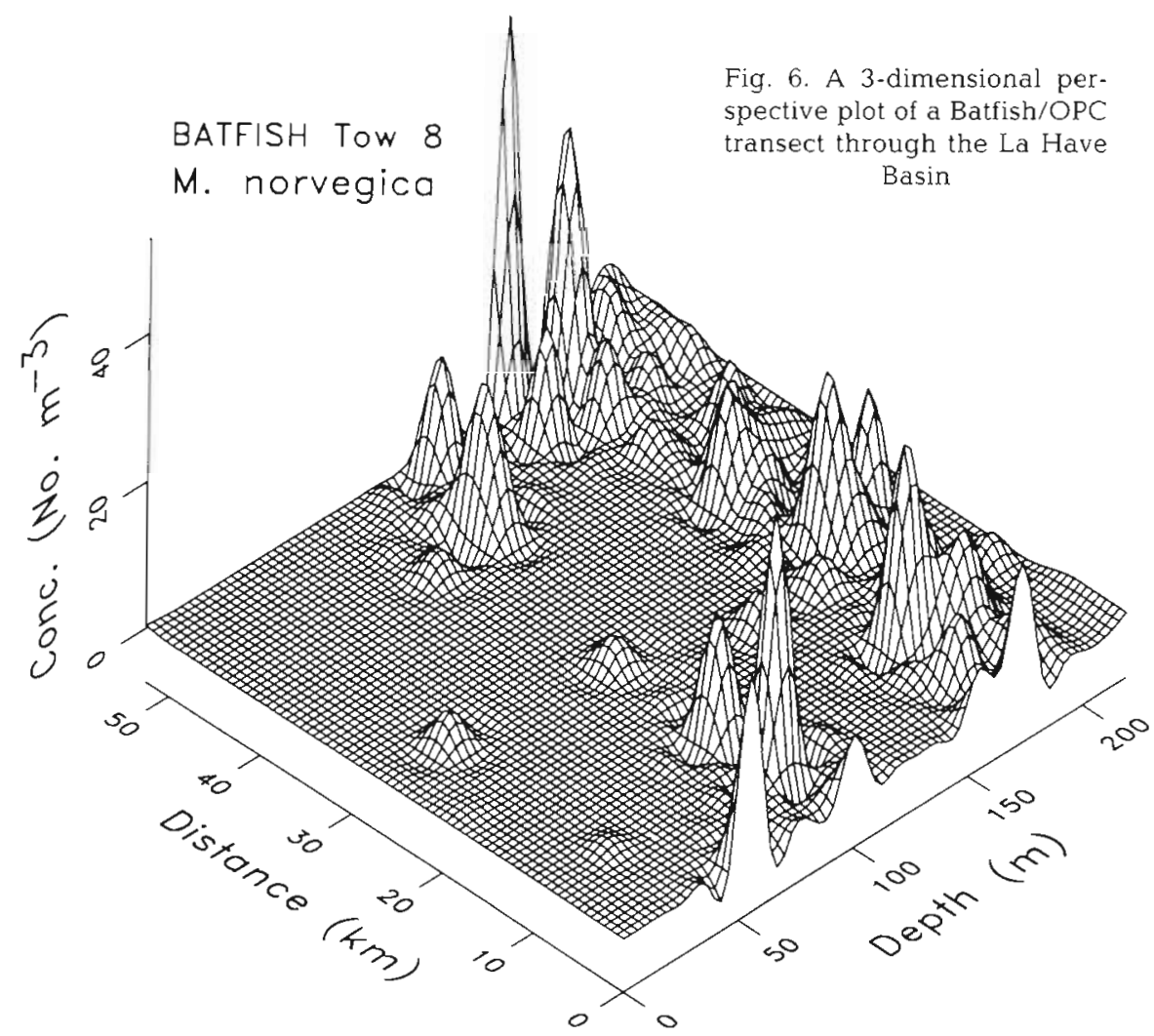

Fig. $9 a$, b shows the results of a similar experiment performed 2 d later. Here we observed a slightly higher concentration of Meganyctiphanes norvegica ranging from 6 to $20 \mathrm{~m}^{-3}$. With the exception of the 2 nd bin-group ( 3 cycle average) of Fig. 9a, the remaining 'lights on' averages were also ca $2 \times$ higher than the 'lights off' averages. Thysanoessa inermis shown in Fig. 9b again displayed only a random pattern for the 'lights on' and 'lights off' experiment.

\section{COMPARISON OF OPC AND ACOUSTIC MEASUREMENTS}

The specific intercomparison described here employed data from the $50 \mathrm{kHz}$ transducer which was effectively limited to the detection of Meganyctiphanes norvegica $>2 \mathrm{~cm}$ in length because of the strong dependence of acoustic target size on scatterer dimension. Batfish Tows 10 and 7 (Figs. $8 \& 9$ ) had to be re-analyzed

of the 3 cycles and plotted in histogram form (Fig. 8a, b). $M$. norvegica concentrations (Fig. 8a) ranged between 2 and $9 \mathrm{~m}^{-3}$, however the mean concentrations for the 'lights on' cycles (dark histogram bars) were ca $2 \times$ higher than the 'lights off' cycles (light histogram bars). Thysanoessa inermis (including $T$. longicaudata) concentrations shown in Fig. $8 \mathrm{~b}$ displayed only a random pattern for the 'lights on' and 'lights off' positions.

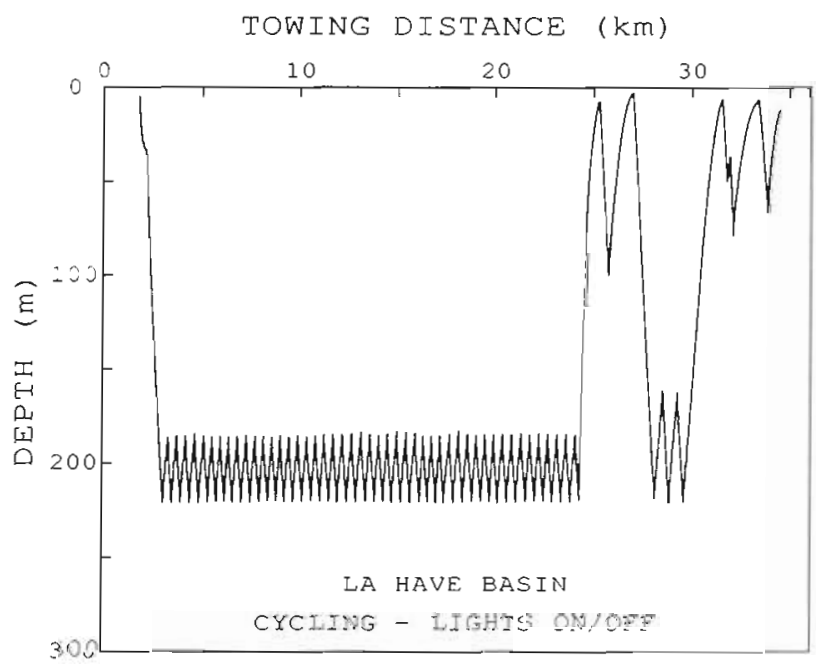

Fig. 7 The depth trace of the Batfish/OPC through a scattering layer situated between 180 and $220 \mathrm{~m}$. Lights were turned 'on' during the first 3 cycles, turned 'off' during the next 3 cycles and subsequently alternated for $M$. norvegica $>2 \mathrm{~cm}$ in length enabling better data comparison with acoustical measurements. However the diameter distributions of $M$. norvegica, e.g. Fig. 4, represent equivalent spherical diameter measurements
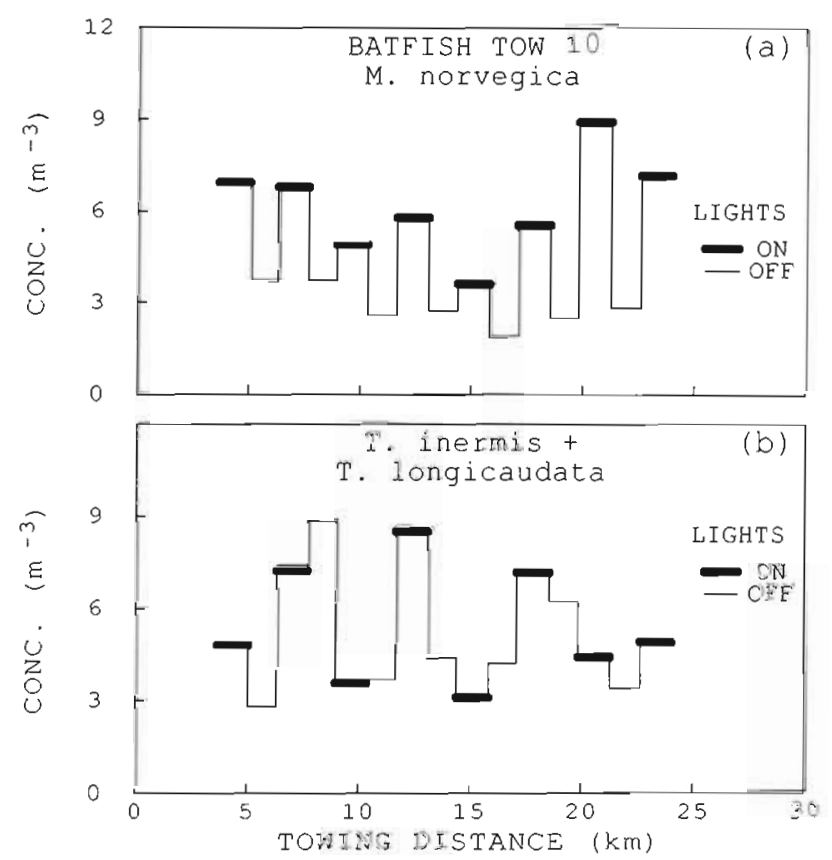

Fig. 8. Results from the first Batfish tow showing the mean concentration of Meganyctiphanes norvegica (a) and Thysanoessa inermis and $T$. longicaudata (b) with alternating 'lights on' (dark bars) and 'Lights off' (light bars) 


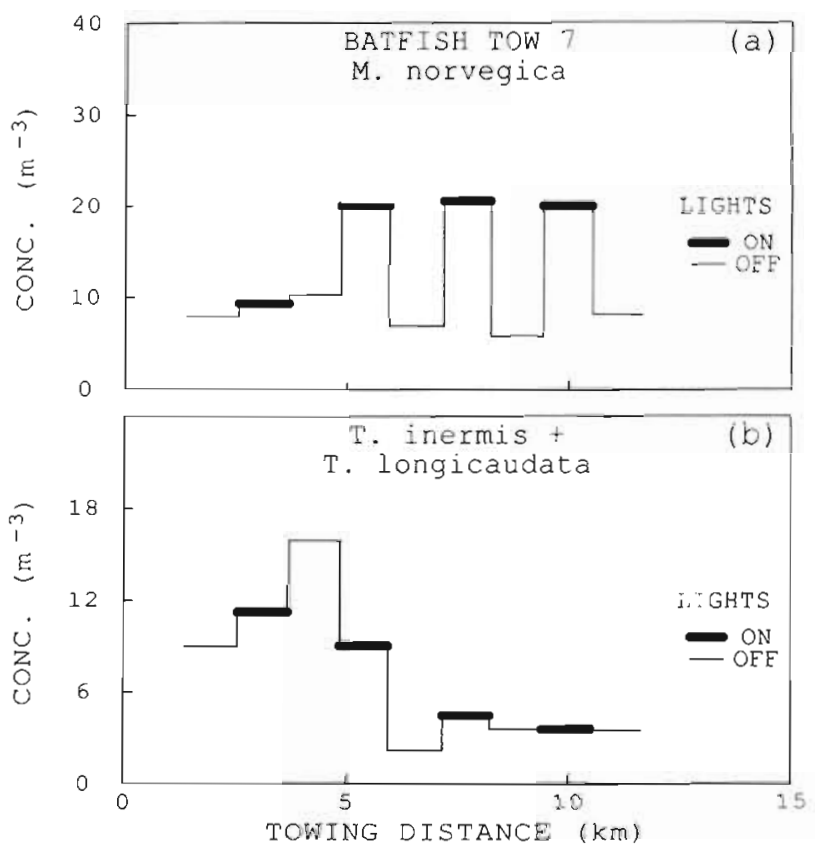

Fig. 9. A second Batfish/OPC tow showing the mean concentration of Meganyctiphanes norvegica (a) and Thysanoessa inermis and T. longicaudata (b) with alternating 'lights on' (dark bars) and 'lights off' (light bars)

only and not those of length. The analyses of the microscopically measured length distributions of $M$. norvegica from BIONESS samples showed 3 distinct peaks corresponding to $1.7,2.2$ and $2.8 \mathrm{~cm}$ in length. The smallest size group of $1.7 \mathrm{~cm}$ representing only $32 \%$ of the total population of $M$. norvegica would not be detected acoustically at a significant level. This size group could then be separated from the diameter distribution by eliminating the lower $32 \%$ of the distribution

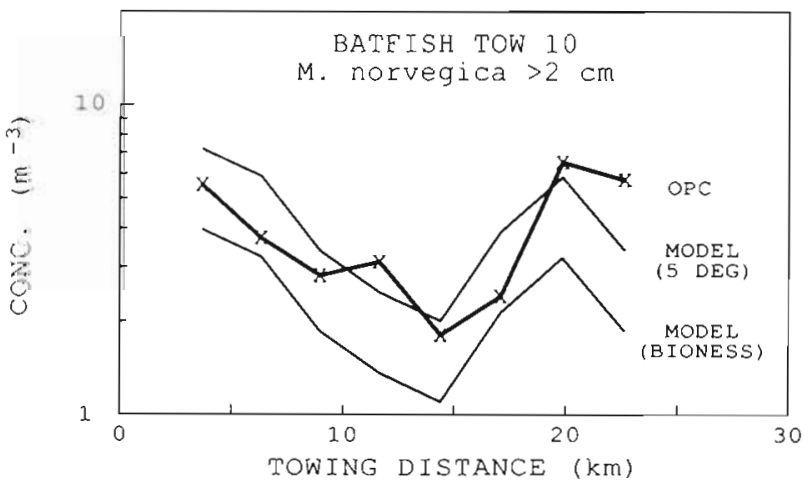

Fig. 10. A comparison of Meganyctiphanes norvegica concentrations measured by the OPC (Tow 10, Fig. 7) using 'lights on' and results from an acoustical tow $(50 \mathrm{kHz})$ in which the acoustical model assumes an animal orientation of $5^{\circ}$. Also shown are the results using an acoustical model in which target strengths have been adjusted to agree with BIONESS catches

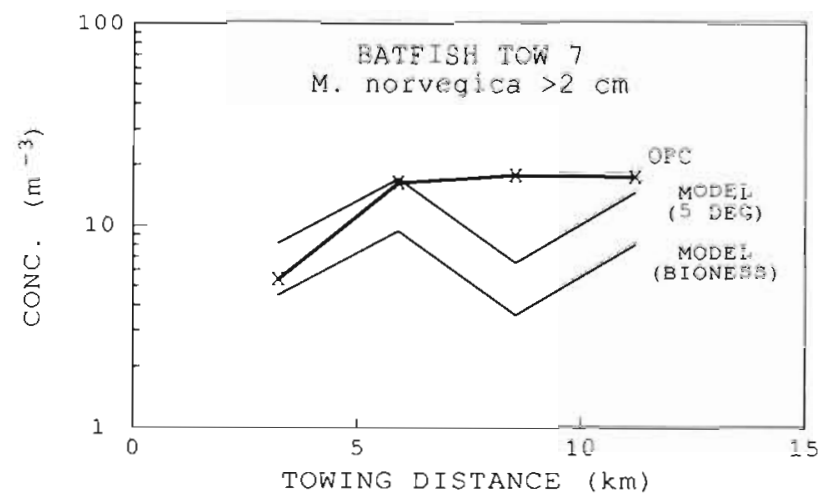

Fig. 11. A comparison of Meganyctiphanes norvegica concentrations measured by the OPC (Tow 7, Fig. 9) using 'lights on' and results from an acoustical tow $(50 \mathrm{kHz})$ in which the acoustical model assumes an animal orientation of $5^{\circ}$ Also shown are the results using an acoustical model in which target strengths have been adjusted to agree with BIONESS catches

which corresponded to 3.0 to $4.0 \mathrm{~mm}$ ESD. Therefore the ESD range between 4.0 and $6.0 \mathrm{~mm}$ corresponded to lengths $>2 \mathrm{~cm}$ for $M$. norvegica and could be usefully compared to acoustical measurements.

Fig. 10 shows the comparison of abundance estimates of Meganyctiphanes norvegica obtained from OPC and acoustical measurements of Tow 10. Each OPC data point represents only the 'lights on' estimates as in Fig. 8, except here data were filtered from 4.0 to $6.0 \mathrm{~mm}$ ESD corresponding to $M$. norvegicá $>2 \mathrm{~cm}$ in length. The mean trend of the resulting $\mathrm{OPC}$ estimates and simultaneous acoustical estimates for Tow 10 using a mean animal orientation of $5^{\circ}$ in the acoustic model are shown in Fig. 10. Both OPC and acoustical curves agree reasonably well both relatively and in magnitude. An additional curve (BIONESS) is shown corresponding to acoustical estimates whereby target strengths used in the acoustic model were adjusted to agree with BIONESS catches. These estimates were ca $2 \times$ lower than those obtained from the OPC.

The 'lights on' data of Tow 7 (Fig. 9) were reanalyzed for the ESD range of 4.0 to $6.0 \mathrm{~mm}$ and are shown in Fig. 11. Agreement between the OPC and acoustical estimates ( $5^{\circ}$ orientation) was also good with the exception of 1 out of 4 data points. The acoustical model using BIONESS estimates were also ca $2 \times$ lower.

\section{DISCUSSION}

Initially 2 avoidance mechanisms were considered, i.e. avoidance of nets due to pressure gradients and avoidance due to visual perception. Our first clue orig- 
inated from the BIONESS tows which yielded lower abundance estimates integrated over the water column (no. $\mathrm{m}^{-2}$ ) during daytime. This observation suggested that 'visual avoidance' played the more important role. The most profound effect of artificial lights on euphausiid avoidance was observed by Sameoto et al. (1990) where increases in euphausiid numbers of 10 to $50 \times$ were observed. Lesser increases by a factor of $2 \times$ with Batfish in the 'lights on' mode is expected since Batfish is towed at higher speeds and the available time for avoidance by euphausiids is significantly decreased.

We also consider here the possibility that abundance estimates of euphausiids may have increased as a result of their reaction and subsequent attraction to the lights. Our observation showed, however, that as long as the vehicle (ROV) was in motion, euphausiids showed no signs of attraction to lights and furthermore, once the vehicle was motionless, the response time was long (>1 min). An artificial light does not appear as a 'point source' to euphausiids but rather as a 'diffuse glow' due to multiple-scattering of light in seawater. As a result euphausiids have no immediate point source to use as a cue which may account for the delay time for the commencement of aggregation at a light source.

The latter discussion was based on visual evidence, however statistical evidence of the effectiveness of the light experiment was also available from all 3 methods of measurements, i.e. OPC, BIONESS and acoustic. Our data have shown that with the use of the light source, all 3 methods yielded results that were convergent to similar values thereby lending confidence to each method. We are not suggesting here that the use of bright lights will yield consistently accurate estimates for all types of net samplers. The first results, however, appear promising and further trials would be required.

The OPC methods described here provide a straightforward measurement of euphausiid abundances by diameter identification. Most euphausiids are significantly larger than copepods (with the exception of some Calanus hyperboreus V \& VI) and are easily separated by their larger diameters which otherwise are free of background counts. Also the measurement of day/night distributions will assist in identifying migrators. Fortunately Scotian Shelf populations of Calanus spp. migrate seasonally only which facilitates the separation of euphausiid data. Euphausiid sizes also are expected to vary seasonally and geographically and net sampling is required for verification.

Acknowledgements. We thank Drs Jeff Runge and Erica Head for their critical review of the manuscript. The efforts of the crew and officers of the CSS 'Dawson' and the staff members of the Metrology Division, in particular, M. Mitchell, S. Young and E. F. Phillips are gratefully acknowledged.

\section{LITERATURE CITED}

Cochrane, N. A., Sameoto, D., Herman, A. W., Neilson, J. (1991). Multiple-frequency acoustic backscatter and zooplankton aggregations in the inner Scotian Shelf basins. Can. J. Fish. Aquat. Sci. 48: 340-355

Everson, I., Bone, D. G. (1986). Effectiveness of the RMT8 system for sampling krill (Euphausia superba) swarms. Polar Biol. 6: 83-90

Francois, R. E., Garrison, G. R. (1982a). Sound absorption based on ocean measurements. Part I: Pure water and magnesium sulfate contribution. J. Acoust. Soc. Am. 72: 896-907

Francois, R. E., Garrison, G. R. (1982b). Sound absorption based on ocean measurements. Part II: Boric acid contribution and equation for total absorption. J. Acoust. Soc. Am. 72: $1879-1890$

Greene, C. F., Wiebe, P. H., Burczynski, J. (1989). Analyzing zooplankton size distributions using high-frequency sound. Limnol. Oceanogr. 34: 129-139

Greenlaw, C. F. (1979). Acoustic estimation of zooplankton populations. Limnol. Oceanogr. 24: 226-242

Herman, A. W. (1988). Simultaneous measurement of zooplankton and light attenuance with a new optical plankton counter. Contin. Shelf Res. 8: 205-221

Herman, A. W. (1992). Design and calibration of a new optical plankton counter capable of sizing small zooplankton. Deep Sea Res. 39: 395-415

Herman, A. W., Dauphinee, T M. (1980). Continuous and rapid profiling of zooplankton with an electronic counter mounted on a 'Batfish' vehicle. Deep Sea Res. 27: 79-96

Herman, A. W., Sameoto, D. D., Chen Shunnian, Mitchell, M. R., Petrie, B., Cochrane, N. (1991). Sources of zooplankton on the Nova Scotia Shelf and their aggregations within deep-shelf basins. Contin. Shelf Res. 11:211-238

Holliday, D. V. (1980). Use of acoustic frequency diversity for marine biological measurements. In; Diemer, F, P., Vernberg, F. J., Merkes, D. Z. (eds.) Advanced concepts in ocean measurements for marine biology. Univ. South Carolina Press, Columbia, p. 423-460

Holliday, D. V., Pieper, R. R. (1980). Volume scattering strengths and zooplankton distributions at acoustic frequencies between 0.5 and $3 \mathrm{MHz}$. J. Acoustic. Soc. Am. 67: 135-146

Pieper, R. R., Holliday, D. V. (1984). Acoustic measurements of zooplankton distributions in the sea. Rapp. P.-v. Réun. Cons. int. Explor. Mer 41: 226-238

Richter, K. E. (1985). Acoustic scattering at $1.2 \mathrm{MHz}$ from individual zooplankters and copepod populations. Deep Sea Res. 32: 149-161

Sameoto, D. D., Herman, A. W. (1990). Life cycle and distribution of Calanus finmarchicus in deep basins on the Nova Scotia Shelf and seasonal changes in Calanus spp. Mar. Ecol. Prog. Ser. 66: 225-237

Sameoto, D. D., Cochrane, N. A., Herman, A. W. (1985) Response of biological acoustic backscattering to ship's lights. Can. J. Fish. Aquat. Sci. 42: 1535-1543

Sameoto, D. D., Cochrane, N. A., Herman, A. W. (1990). Use of multiple frequency acoustics and other methods estimating copepod and euphausidd abundances. ICES theme session on measurement of zooplankter rates and biomass characteristics. Comm. Meet. int. Coun. Explor. Sea C.M.ICES/L:81 
Sameoto, D. D., Cochrane, N. A., Herman, A. W. (1993). Convergence of acoustic, optical, and net-catch estimates of euphausiid abundance; the use of artificial light to reduce net avoidance. Can. J. Fish. Aquat. Sci. (in press) Sameoto, D. D., Jarosynski, L. O, Fraser, W. B. (1980). The

This article was submitted to the editor
BIONESS - new design in multiple net zooplankton samplers. J. Fish. Res. Bd Can. 37: 722-724

Wiebe, P. H., Burt, K. H., Boyd, S. H., Morton, A. W. (1976). A multiple opening/closing net and environmental system for sampling zooplankton. J. mar. Res. 34: 313-326

Manuscript first received: June 16, 1992

Revised version accepted: February 10, 1993 